Cahiers $d u$ MONDE RUSSE

\section{Cahiers du monde russe}

Russie - Empire russe - Union soviétique et États indépendants

$48 / 4 \mid 2007$

Varia

\title{
Tomohiko Uyama, éd., Empire, Islam, and Politics in Central Eurasia
}

\section{Sébastien Peyrouse}

\section{OpenEdition \\ Journals}

Édition électronique

URL : https://journals.openedition.org/monderusse/6112

DOI : 10.4000/monderusse.6112

ISSN : $1777-5388$

Éditeur

Éditions de l'EHESS

\section{Édition imprimée}

Date de publication : 2 décembre 2007

Pagination : 793-795

ISBN : 978-2-7132-2148-4

ISSN : $1252-6576$

Référence électronique

Sébastien Peyrouse, "Tomohiko Uyama, éd., Empire, Islam, and Politics in Central Eurasia », Cahiers du monde russe [En ligne], 48/4 | 2007, mis en ligne le 16 juin 2009, consulté le 03 septembre 2022. URL : http://journals.openedition.org/monderusse/6112; DOI : https://doi.org/10.4000/monderusse. 6112

Ce document a été généré automatiquement le 3 septembre 2022.

Tous droits réservés 


\title{
Tomohiko Uyama, éd., Empire, Islam, and Politics in Central Eurasia
}

\author{
Sébastien Peyrouse
}

\section{RÉFÉRENCE}

Tomohiko UyAma, éd., Empire, Islam, and Politics in Central Eurasia. Sapporo : Slavic Research Center, Hokkaido University, 2007, 376 p. (21st Century COE Program Slavic Eurasian Studies, 14)

1 Le volume regroupe les communications au colloque «Regional and Transregional Dynamism in Central Eurasia: Empires, Islam and Politics» tenu à Sapporo en juillet 2005. Bien qu'un certain nombre d'articles soient le fait de chercheurs américains, russes ou centrasiatiques, l'ouvrage donne une idée assez précise du développement rapide au Japon des études sur l'Asie centrale, tout particulièrement du rôle fondamental qu'y joue le Slavic Research Center de l'université de Sapporo. L'objectif du recueil est de mieux cerner les interactions entre dynamiques régionales internes et dynamiques transrégionales externes en «Eurasie centrale ». Dans ce large cadre, particulièrement pertinent pour cette zone, plusieurs thématiques ont été retenues.

2 La première partie en quatre articles se focalise sur l'influence de l'empire tsariste en Asie centrale et éclaire cette question à partir de nouvelles sources. Hisao Komatsu s'intéresse à la réaction des théologiens musulmans turkestanais à la conquête russe et aux débats sur les conditions d'exercice de l'islam dans l'Empire. Contrairement à une idée répandue, bien des théologiens ont considéré la Russie comme faisant partie du Dar alIslam, puisque les juges islamiques (qadi) pouvaient exercer leur juridiction en accord avec la charia. L'autonomie de gestion laissée aux autochtones a donc joué un rôle important dans cette vision positive, ou pour le moins résignée, de la colonisation. Par ailleurs, certains oulémas ont accepté la conquête russe car elle permettait la modernisation du Turkestan, ce qui les a conduits à condamner la révolte d'Andidjan de 1898 et les religieux conservateurs intégristes qui la menaient. 
3 Cette étude de l'influence de la Russie tsariste au Turkestan est complétée par celle de Tomohiko Uyama qui revient sur deux enjeux clés de la colonisation des steppes kazakhes : la christianisation des nomades et la conscription des Centrasiatiques. Comme l'auteur le démontre, les administrateurs russes ont longuement hésité à répondre aux demandes de l'Église et ont préféré éluder le prosélytisme orthodoxe. De même, la conscription a été envisagée avec nuances dans le cadre des tensions avec la Chine et des risques de guerre avec les Britanniques en Afghanistan, jusqu'à ce qu'elle apparaisse incontournable en 1916. L'article apporte également un regard original sur les administrateurs russes acceptant mal que certains intellectuels musulmans s'identifient à la Russie et la présentent comme leur patrie. Ceci confirme que la volonté de domination de l'Asie centrale ne signifiait pas nécessairement le désir d'une acculturation des nomades.

4 Norihino Naganawa prolonge cette réflexion pour la région Volga-Oural. Comparant les provinces de Kazan, Ufa et Orenburg, il étudie la réaction des djadids, des enseignants de madrasas et des oulémas face à la concurrence du ministère de l'Éducation nationale et des zemstva, qui cherchent à maîtriser l'éducation des allogènes. Il semble bien qu'alors les enseignants religieux se soient, paradoxalement, sentis moins concurrencés par les écoles russes que par les djadids, qui prônaient eux aussi une éducation laïque. Ce point de vue novateur permet de repenser les différentes combinaisons possibles entre culture des identités nationales et appartenance citoyenne dans la Russie du XIX ${ }^{\mathrm{e}}$ siècle. Le dernier article consacré à cette période, celui de Margaret Dikovitskaia, revient sur les attitudes coloniales des Russes envers les Centrasiatiques à travers une approche originale, l'analyse des photographies ethnographiques de l'époque. Qu'il s'agisse de publications officielles, comme Turkestanskij al'bom [Album du Turkestan] et Tipy narodnostej Srednej Azii [Types des nationalités d'Asie centrale], ou des photographies en couleur de S.M. Prokudin-Gorskij, toutes révèlent les vues orientalisantes des Russes installés au Turkestan et leur volonté de créer un « exotisme » centrasiatique.

5 La deuxième et la troisième partie de l'ouvrage sont consacrées à la période soviétique et poursuivent pour le $\mathrm{xx}^{\mathrm{e}}$ siècle l'étude des interactions entre dynamiques externes et internes au travers des questions religieuse et nationale. Adeeb Khalid réexamine par exemple l'histoire des djadids en se penchant plus particulièrement sur leur rapport au pouvoir bolchevik. Il montre avec justesse combien ils ont été poussés par la révolution d'Octobre à donner la priorité à l'action politique plutôt qu'aux réformes culturelles. Leur autonomie de décision, en particulier à Boukhara avant 1924, ainsi que leurs engagements « anticolonialistes » furent toutefois de courte durée, le nouveau pouvoir central refusant rapidement toute expression de divergence politique et identitaire. Dans cette perspective, Mambet Koigeldiev analyse les conflits survenus entre les bolcheviks et les intellectuels kazakhs d'Alash Orda dans les premières années du régime. À partir d'archives et de correspondances, elle éclaire l'organisation de leur liquidation politique et physique, décidée entre autres par le premier secrétaire du PC kazakh, Gološčekin, et l'OGPU.

6 Le thème de l'islam s'efface alors pour laisser place aux questions nationales, analysées ici sous l'angle des « peuples punis ». Ainsi, Elza Blair-Guchinova décrypte avec finesse les stratégies de survie des Kalmouks déportés en Sibérie en 1943, ainsi que leur capacité à renforcer une identité ethnique pourtant stigmatisée. Shiro Hanya, quant à lui, se focalise sur les « peuples punis » n'ayant pu rentrer dans leur région d'origine lors de la déstalinisation des années 1950. À travers l'exemple des Allemands, des Tatars de Crimée 
et des Meskhètes, il propose une analyse très stimulante de la politique des nationalités sous Brežnev. En effet, l'arrivée de Jurij Andropov à la tête du KGB en 1967 permit aux «peuples punis » de revendiquer plus ouvertement leur volonté de réhabilitation. Le pouvoir central, alors à la recherche de compromis, envisage, dans les années 1970, la création d'une région autonome allemande au Kazakhstan et d'un district autonome tatar en Ouzbékistan, avant de revenir sur ses promesses face à une virulente réaction des Kazakhs qui confirmait la montée des tensions interethniques dans la région. On placera ici l'article d'Achirbek Muminov, situé en quatrième partie mais consacré à la naissance d'un islam radical en Union soviétique, et en particulier au rôle joué par Shami Damulla et ses descendants en Ouzbékistan.

7 Les quatrième, cinquième et sixième parties sont dédiées à la période post-soviétique. Bien que beaucoup plus disparates thématiquement, certains articles n'en demeurent pas moins excellents. Ainsi, George Sanikidze étudie avec minutie la naissance d'un islam radical dans la vallée de Pankisi en Géorgie, lieu rendu célèbre par les combats russotchétchènes en 2000. Il cherche à démontrer que, contrairement à la Tchétchénie ou au Daghestan, jusqu'à très récemment l'islam dans cette région n'avait jamais joué de rôle important. $\mathrm{Au} \mathrm{XIX}^{\mathrm{e}}$ siècle, il se trouvait en concurrence avec les missionnaires chrétiens russes et géorgiens qui tentaient de convertir les Kists, avant que, à la période soviétique, les confréries soufies Naqshbandiyya et Qadiriyya ne s'y implantent massivement. L'islamisme dans sa version djihadiste n'arrive que tardivement dans la région, dans la deuxième moitié des années 1990, avec l'afflux de militants tchétchènes et arabes. Cette vallée se trouve maintenant prise dans une dynamique de déstabilisation due au conflit tchétchène, à l'afflux de réfugiés, au trafic de drogue et d'armes, mais également aux tensions entre Russie et Géorgie.

Les quatre derniers articles sont consacrés à des thématiques plus strictement politiques de l'évolution des nouveaux États dans les années 1990-2000. Plusieurs questions cruciales y sont évoquées: construction d'un système politique kazakh fondé sur des groupes d'intérêts plus ou moins liés au pouvoir grandissant du président Nursultan Nazarbaev (Dosym Satpaev); recherche d'une certaine stabilité constitutionnelle et d'un régime semi-présidentiel en Arménie (Alexander Markanov); difficultés à maittriser le trafic de drogue passant par la frontière russo-kazakhe (Sergey Golunov); tentatives des minorités ouzbèke et ouïgour au Kazakhstan, qui ne présentent pas de menace transfrontalière particulière, pour au contraire trouver leur place au sein de la nouvelle société kazakh (Natsuko Oka).

9 Cet ouvrage apporte donc de nombreux éléments de réflexion et de nouvelles pistes de recherche concernant l'Asie centrale, en particulier pour le xIX siècle et la période soviétique. Il confirme également l'institutionnalisation d'une école nippone d'études de l'Asie centrale, ayant accès aux sources en russe, en persan et en langues vernaculaires, centrée sur les grands enjeux historiques et contemporains de la région, en particulier l'islam, la question nationale et l'interaction avec le monde russe. 